\title{
Formação de professores em educação ambiental crítica centrada na investigação-ação e na parceria colaborativa
}

\author{
Teacher training in critical Environmental Education \\ centered in research-action and collaborative partnership
}

\author{
José Pedro de Azevedo Martins ${ }^{1}$ \\ https://orcid.org/0000-0001-8141-5280 \\ Roseli Pacheco Schnetzler ${ }^{2}$ \\ https://orcid.org/0000-0003-1163-6891
}

\begin{abstract}
Resumo: Este trabalho analisa um programa de formação continuada de professores em educação ambiental crítica, centrado na Investigação-Ação em Parceria Colaborativa, com foco em mudanças na prática docente proporcionadas pela abordagem teórico-metodológica adotada. Para isso, foi constituído um grupo de pesquisa composto por 15 professores da escola básica, três professores universitários e quatro licenciandos. As reuniões do grupo ocorriam, quinzenalmente, durante um ano, em que foram desenvolvidos três tipos de atividades: Oficinas de Formação e Diagnósticos, Ação Escolar de Ensino e Pesquisa e Oficinas de Socialização de Experiências. Os resultados mostram que pela socialização das experiências de ensino, os professores foram, paulatinamente, modificando suas práticas docentes, inicialmente pontuais e compartimentalizadas; no decorrer do trabalho, tais práticas foram alteradas com a inclusão de temáticas socioambientais abordadas de forma crítica, contextualizada, permanente, contínua e participativa.
\end{abstract}

Palavras-chave: Formação continuada de professores. Educação ambiental crítica. Investigação-ação. Parceria colaborativa.

\begin{abstract}
This article analyzes a teacher-training program in critical environmental education centered on research-action and collaborative partnership. A research group was created, composed of 15 elementary and secondary teachers, 3 lecturers and 4 undergraduate students, which had fortnightly meetings, during a period of one year, by developing three types of activities: Training and Diagnostics Workshops, School Action Research and Socialization of teachers' experiences. The results reveal that due to the socialization of educational experiences, teachers were gradually changing their teaching practice, initially compartmented to practices in which environmental issues are contextualized, permanent, continuous and participatory.
\end{abstract}

Keywords: Teacher training. Critical environmental education. Action-research. Collaborative partnership.

\footnotetext{
${ }^{1}$ Universidade Federal do Sul e Sudeste do Para (UNIFESSPA), Instituto de Ciências Humanas, Faculdade de Ciências da Educação, Marabá, PA, Brasil. E-mail: <jotapam@unifesspa.edu.br>.

${ }^{2}$ Universidade Metodista de Piracicaba (UNIMEP), Piracicaba, SP, Brasil.
} 


\section{Introdução}

Para autores como Carr e Kemmis (1997), Contreras (1994), Schnetzler (2000) e outros que se apoiam nas racionalidades prática e crítica situadas na Epistemologia da Prática e na pesquisa sobre formação de professores e ação docente, a Investigação-Ação (I-A) é uma importante abordagem metodológica, não apenas para a produção de conhecimentos nesta área, mas, também, para a formação de professores enquanto pesquisadores de suas próprias práticas. No campo da formação de professores, em geral, tem prevalecido um modelo de pesquisa que não discute questões como: a investigação sobre os processos educacionais cotidianos pode promover a melhoria destes? Quais? Como? A perspectiva de investigação adotada contribui para a formação continuada dos professores envolvidos no processo formativo? De que forma?

A pesquisa que deu origem a este artigo foi conduzida com base nos princípios da I-A e da Parceria Colaborativa, com o objetivo principal de estudar a formação continuada de professores educadores ambientais. Foi baseada, também, nos princípios da educação ambiental (EA) crítica (CARVALHO, 2001; GUIMARÃES, 2004; TOZONI-REIS, 2008), guiada por questões como: Esta abordagem pode contribuir diretamente para a formação? De que forma? Como os professores podem desenvolver um ensino crítico de temas ambientais, superando o caráter fragmentado e pontual das práticas dominantes, da visão disciplinar quando envolvidos num processo de Investigação-Ação da própria prática?

O cenário socioambiental central onde se desenvolveu a pesquisa se localiza na região de Marabá/Carajás, Sudeste do Pará, a qual, até o início da década de 1970, caracterizou-se pela exuberância de sua floresta e biodiversidade como palco marcante de culturas indígenas. Atualmente, no entanto, como discute Hébètte (2004), é uma região em que predominam intensa exploração de madeira nativa, pecuária extensiva, constantes conflitos pela posse da terra com assassinatos de trabalhadores do campo e ambientalistas e a forte exploração e industrialização mineral. São atividades causadoras da intensa devastação da floresta amazônica, na região, da destruição de comunidades e culturas indígenas e de inúmeros habitats ameaçando de extinção muitas espécies nativas, vegetais e animais.

Os governos, por sua vez, pouco fizeram para a reversão desse quadro, seja por despreparo técnico e moral, seja por (des)interesses pessoais. Um dos setores da sociedade que mais sofreu as consequências desse tratamento foi o da educação. Tanto o ensino informal praticado no seio das comunidades, como o ensino formal praticado na educação básica e a formação de professores continuam sendo negligenciados pela administração pública regional. A ausência de discussões sobre os fenômenos e os problemas sociais e ambientais da região contribui, gradativa e indiretamente, para o agravamento destes problemas. Como consequência, cidades, escolas e assentamentos da região apresentam-se, cada vez mais, inundados de dejetos de toda sorte (MARTINS, 2016).

A falta de planejamento urbano e de políticas públicas adequadas, associada à prática cotidiana da população quanto ao despejo de dejetos ao longo das vias terrestres e fluviais e em muitos logradouros públicos de vilas e cidades, denuncia a ausência de uma prática de EA eficaz na região, transformando cidades e vilas em locais impróprios para a convivência humana. Diante desse quadro, uma questão se apresenta: que perspectiva de EA poderá se antepor a esse estado de degradação e violência que impera na região, contribuindo para a reversão do mesmo? 


\section{A Educação Ambiental pela qual lutamos}

Já não são mais raras, como destaca Guimarães (2004), iniciativas escolares reconhecidas pela comunidade acadêmica como a de EA. Para este autor, a institucionalização da EA reflete essas demandas e impulsiona as escolas a desenvolverem ações neste campo. Esse processo parece dar-se mais "como parte dos efeitos conquistados pela legitimidade da temática ambiental” (CARVALHO, 2001, p. 75).

Certamente, como fenômeno social relativamente recente, trata-se de uma resposta à demanda gerada pela crise ambiental, intensamente estudada pela comunidade científica nacional e internacional, de modo a considerar que tal fenômeno tem potencializado a emergência da EA. Se, no princípio, predominou, nesse campo do conhecimento, um olhar marcadamente voltado para a dinâmica da natureza, em detrimento da dinâmica da sociedade, podemos afirmar que os trabalhos mais recentes refletem uma transição histórica para uma fase que incorpora referenciais sociológicos, filosóficos e psicossociológicos à dinâmica social sobre o ambiente, assim como, concepções políticas, econômicas e culturais que orientam essa nova abordagem (CARVALHO, 2000; TOZONI-REIS, 2008).

A participação dos professores escolares nesse debate e, consequentemente, na construção de propostas para enfrentamento dessa crise, é fundamental, tanto pelo papel social que ocupam, como pela capacidade de influência exercida sobre a opinião da comunidade. Essa participação vem sendo estimulada pela própria esperança generalizada da sociedade em relação ao papel da educação na superação de problemas ambientais. Crespo e Leitão (1993) identificaram que a crença na EA como uma grande saída para a crise, é um consenso entusiasticamente defendido por todos. Segundo estes autores, para 95\% dos brasileiros, a EA deve ser obrigatória nas escolas.

Apesar da expectativa dos brasileiros em relação ao potencial da EA, esta, como os demais campos do conhecimento científico, não se apresenta como um campo monolítico de teorias e práticas. Pelo menos duas grandes tendências que envolvem outras vertentes disputam a hegemonia na inserção da dimensão ambiental na educação escolar. Uma delas, ligada aos interesses populares de emancipação, igualdade, justiça social e melhor qualidade de vida que se expressa em melhor qualidade ambiental, é denominada de EA crítica (CARVALHO, 2001); a outra, cujos protagonistas ou veiculadores assumem, astuta ou ingenuamente, os interesses do capital e da lógica do mercado, conservando valores e princípios defendidos por grupos sociais ideologicamente dominantes, é considerada como conservadora e hegemônica na constituição da sociedade.

Adotamos esta categorização para enfatizar certa indisposição no meio escolar em operar mudanças que contribuam, efetivamente, para a superação da exploração social e ambiental, desconsiderando as dimensões e relações econômicas, políticas e ideológicas presentes nos problemas socioambientais. Estamos cientes, no entanto, de que há outras formas de análises, como a que realiza a Ciência, Tecnologia, Sociedade e Ambiente (CTSA), importante abordagem para o ensino de ciências na educação básica (FARIAS; FREITAS, 2007), que, exitosamente, consideram as dimensões acima mencionadas.

Um novo consenso de que a temática ambiental não é um conteúdo a ser somado às disciplinas curriculares tradicionais foi se formando, embora tenha enfrentado muitas resistências 
nas práticas do cotidiano escolar (GUIMARÃES, 2004). A visão fragmentária mobilizada numa concepção conservadora potencializa nas escolas - contrariamente ao que se defende numa abordagem crítica - uma forte tendência ao desenvolvimento de ações isoladas voltadas para o comportamento individual de cada aluno e descontextualizadas da realidade socioambiental em que a escola se encontra inserida. Segundo Carvalho (2001), a EA, no ensino fundamental, tem se dado através de projetos pontuais e extracurriculares, apenas por iniciativas isoladas de professores, caracterizando-se como uma dinâmica voluntarista e periférica ao sistema escolar.

$\mathrm{Na}$ perspectiva de construção de uma sociedade que busca a igualdade de direitos entre seus membros, faz-se necessária uma EA que assuma um caráter crítico diante dos problemas ambientais e sociais, ou seja, faz-se necessária uma EA que seja crítica às desigualdades sociais e aos desequilíbrios nas relações entre sociedade e natureza; que aborde os problemas ambientais como decorrentes dos conflitos entre interesses privados e coletivos, permeados e mediados por relações de poder; que se volte para a construção de uma cidadania ativa, cujo exercício forneça aos educandos e educadores instrumentos para a compreensão de realidades complexas. Numa abordagem crítica da EA, ser cidadão exige uma atuação política na esfera social, uma vez que, segundo Bárcena (1997 apud GUTIERREZ; PRADO, 1999, p. 15), quando o indivíduo se organiza e participa na direção de sua própria vida, adquire poder político e capacidade de mudança coletiva.

Desta perspectiva, defendemos uma EA comprometida com os interesses das classes populares, dos oprimidos, conforme discute Freire (1992). Defendemos o exercício de uma prática educacional vinculada à prática social contextualizada na realidade socioambiental, não devendo tal prática ficar restrita à mera transmissão do conhecimento ou voltada simplesmente para a mudança de comportamentos individuais, tal como uma educação contemplativa.

\section{A formação de professores como educadores ambientais}

Na perspectiva da formação de professores em EA, as pesquisas indicam (TRISTÃO, 2004) que ações pontuais com abordagens naturalistas e/ou antropocêntricas não têm sido suficientes para a incorporação da dimensão ambiental no currículo de formação de professores, nem para a institucionalização da EA. Tais estudos têm mostrado que a EA, em muitos casos, continua sendo abordada de forma tradicional e conservadora, predominando práticas que revelam a necessidade de rompimento do modelo conservador de educação e desenvolvimento de uma EA crítica e emancipatória que garanta seu próprio fortalecimento na formação dos professores. Há consenso entre autores de que a EA crítica não é assumida pelos cursos de licenciaturas de forma sistemática, evidenciando uma dificuldade do professor formador em trabalhar temáticas ambientais integradas ao conteúdo de seu ensino acadêmico (GUIMARÃES, 2004; LOUREIRO, 2004).

Nesse sentido, diferentes perspectivas têm sido utilizadas na formação inicial e continuada de professores em EA, levando-nos a questionar o enfoque dado para o desenvolvimento de conhecimentos, habilidades, valores e ações efetivas, necessárias à inserção da dimensão ambiental nos currículos de formação de professores (MARTINS, 2016). Nesse sentido, defendemos que o processo de formação docente em EA não deve se reduzir ao treinamento, capacitação, nem à transmissão de conhecimentos. Ele deve ser, acima de tudo, uma reconstrução de valores éticos, da práxis refletida, um processo de reflexão crítica. Pimenta e Ghedin (2002) afirmam 
que a reflexão sobre as contradições no processo de formação de professores ganha uma outra dimensão quando centrada na investigação do próprio trabalho em sala de aula e na escola.

O professor, na escola ou em formação nas universidades, é sempre demandado social e institucionalmente a inserir a dimensão ambiental em suas ações pedagógicas. No entanto, apesar das demandas recebidas, quase sempre continua tendo sua formação na mesma perspectiva conservadora de educação que produz a "armadilha” paradigmática, no sentido postulado por Guimarães (2004). Trata-se de uma perspectiva que produz uma dada compreensão de mundo forjada pela racionalidade dominante geradora de práticas e concepções incapazes de contrapor o caminho único prescrito por essa racionalidade.

Neste trabalho, situamos nossas reflexões numa perspectiva segundo a qual a EA não é apenas comunicação ambiental, ou seja, não é somente a ação que visa apenas informar normas ou conhecimentos técnicos sobre a dinâmica da Natureza. Estabelecer uma equivalência entre EA e comunicação é acreditar que apenas a transmissão da informação ambiental correta é suficiente para uma mudança de comportamento individual e coletiva em relação ao ambiente e à sociedade. Trata-se de uma visão reducionista e conservadora da educação que, ao não vislumbrar e promover transformações, ajusta-se à reprodução do status quo.

Portanto, a formação de um educador ambiental não deve se reduzir a um instrumental técnico/metodológico, como parece ser a tendência criticada por Guimarães (2004). Contrariamente, uma abordagem situada numa EA crítica deve propiciar uma formação político-filosófica para além do instrumental técnico/metodológico, de modo a capacitar o educador como uma liderança apta a contribuir na construção de ambientes educadores críticos e a criar condições de resistência e de superação da racionalidade dominante no processo sócio-histórico atual. Neste sentido, indagamos: que racionalidade é capaz de proporcionar as bases para esta empreitada? Sob quais bases teórico-metodológicas ela se constitui?

\section{Investigação-Ação e Parceria Colaborativa: as bases do percurso}

Nas últimas décadas, o entendimento de que o professor necessita desenvolver conhecimentos que o conduzam à compreensão da própria prática, pela investigação desta, tem levado pesquisadores e formadores de professores a se debruçarem sobre questões como as enunciadas anteriormente, propondo diversas modalidades de atividades que possam contribuir para a formação desse professor como pesquisador de sua prática em ação escolar. Para Grígoli et al. (2007), trata-se de um profissional que deverá investir em novas práticas capazes de promover uma intervenção qualificada, potencializando e propiciando, assim, as influências da educação escolar no contexto social.

A I-A, na educação, apresenta-se como um meio pelo qual os professores possam compreender e desenvolver seus valores educativos, mediante uma reflexão sistemática sobre seu ensino escolar (STENHOUSE, 1993). Constitui-se, nesse sentido, uma via para o estudo de práticas e concepções que os professores mobilizam cotidianamente em sua ação docente (SCHNETZLER, 2000). Nessa perspectiva, o professor desenvolve sua reflexão a partir da sistematização dos saberes que embasam suas práticas pedagógicas, promovendo mudanças a partir da investigação. Constitui-se, portanto, num método de investigação que exige a reflexão e a autorreflexão dos sujeitos participantes sobre a constituição de seus saberes, fazeres e posições frente a situações problematizadas em sua ação educativa formal (PEREZ-GÓMEZ, 1992). 
Para Contreras (1994, p. 12), esta é “[...] uma abordagem pela qual o professor pode reconstituir seu conhecimento profissional como parte do processo de construção de discursos públicos unidos à prática, aos problemas e necessidades". Para que os professores atinjam tal objetivo, necessitam refletir, discutir, dialogar, pesquisar e problematizar coletivamente suas práticas e os contextos dos quais fazem parte, promovendo “[...] uma indagação sistemática e autocrítica. A pesquisa, como indagação baseada na curiosidade, no desejo de compreender torna-se uma tarefa cotidiana”. (STENHOUSE, 1986 apud DICKEL, 2001, p. 52).

Segundo Carr e Kemmis (1988, p. 174, tradução nossa), a I-A é uma forma de questionamento auto-reflexivo realizado pelos membros de uma comunidade investigadora crítica sobre situações sociais, cujo objetivo é "melhorar a racionalidade e a justiça de suas próprias práticas, sua compreensão das mesmas e as situações dentro das quais elas têm lugar”. Desta forma, para estes autores, a I-A se torna um caminho que possibilita a ação política e social desenvolvida pelos membros de um grupo cujo objetivo é a transformação educacional a partir da participação efetiva destes em elaborações e decisões a serem conduzidas durante as práticas educativas, em "um processo de interação por meio do qual o pensamento e a ação se reconstroem permanentemente no seio do processo histórico vivo, que se manifesta em toda a situação social real" (CARR; KEMMIS, 1997, p. 51, tradução nossa). A I-A se caracteriza como um processo contínuo de ação, observação, reflexão, nova ação em que a análise da ação e a reflexão sobre ela, ou seja, sobre os problemas que se interpõem aos objetivos da ação, é sempre um processo inacabado, uma vez que toda reflexão conduz a uma reelaboração da prática, gerando nova ação, desenhando um modelo espiralar de desenvolvimento da I-A (CONTRERAS, 1994, 2002).

As pesquisas sobre a formação docente vêm mostrando, também, a importância do trabalho colaborativo como instância de desenvolvimento profissional, uma vez que proporciona condições de formação permanente, troca de experiências, busca de inovações e de soluções para os problemas que emergem do cotidiano escolar (NACARATO, 2005). Desta forma, a I-A se constitui como uma forma de compreender o ensino como um processo político de construção coletiva permanente, pela reflexão na e sobre a prática. Essa compreensão conduz à noção de Parceria Colaborativa na investigação da prática enquanto modalidade de pesquisa científica. Para Schneztler (2002), o trabalho colaborativo é marcado pelo trabalho conjunto entre professores universitários e professores escolares, podendo envolver estudantes de licenciatura e de pós-graduação em um apoio mútuo cuja definição de objetivos comuns é coletiva e cujas relações não podem ser hierarquizadas, mas constituídas de uma liderança compartilhada.

Em linhas gerais, numa I-A em Parceria Colaborativa, as questões de ensino, principalmente aquelas que dizem respeito a dificuldades e angústias identificadas pelos professores em sua prática escolar cotidiana, são socializadas e problematizadas pelo grupo, numa reflexão coletiva. A partir da reflexão coletiva são mobilizados elementos teóricos para ampliar e aprofundar a compreensão de fatores envolvidos na situação geradora das dificuldades e conflitos. Num processo de construção coletiva são formuladas propostas de ação que, na sequência, são implementadas e reavaliadas em sala de aula. São elaborados registros cuidadosos dos acontecimentos, dos desdobramentos, das impressões causadas, das reações dos alunos, dos resultados constatados, para que, em um momento posterior, sejam apreciados colaborativamente no coletivo investigativo, visando o aprofundamento de análises e interpretações da experiência. 


\section{A trilha percorrida}

Para a condução do processo investigativo/formativo aqui discutido, as atividades foram agrupadas em três frentes de investigação/formação: Oficinas de Formação e Diagnósticos (OFD), Atividades de Ensino e Pesquisa (AEP) e Oficinas de Socialização de Experiências $(\mathrm{OSE})^{3}$ (Figura 1).

Figura 1. Desenvolvimento espiralar da pesquisa de campo com a distribuição de OFD, AEPs e OSEs

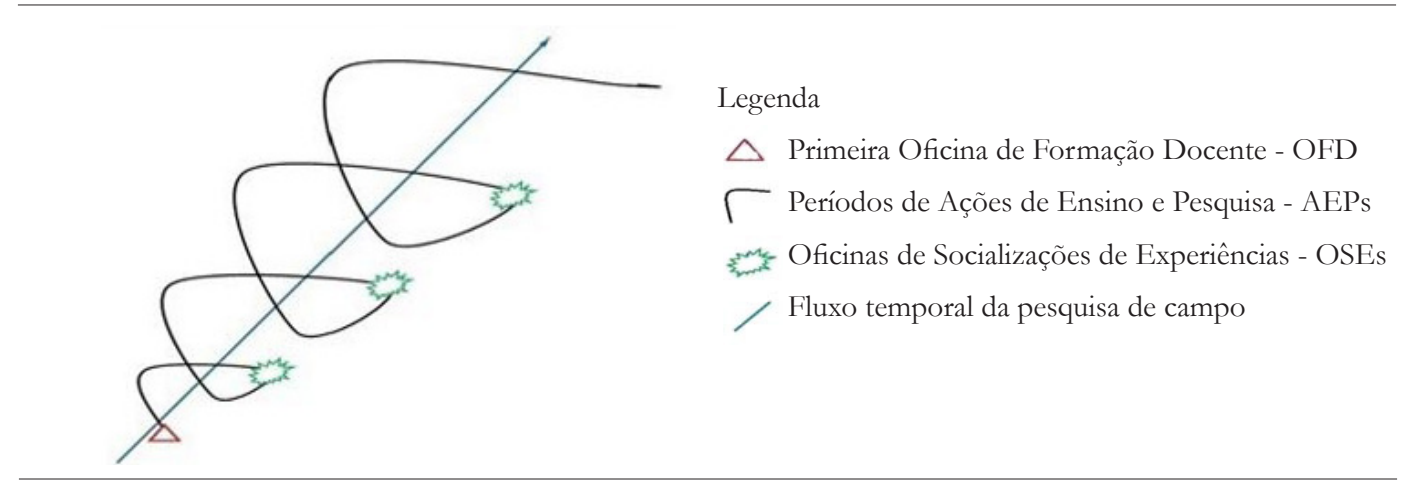

Fonte: Elaborado pelos autores com base em Contreras (2002)

As OFD compreenderam: atividades voltadas para o diagnóstico do quadro socioambiental e educacional da região; apreensão de conceitos, princípios e teorias relacionados aos referenciais teóricos adotados; definição de temas ambientais ligados aos problemas regionais; construção colaborativa de planos de ação/ensino para a inserção de temáticas socioambientais nas escolas e avaliação das atividades. Estas atividades foram desenvolvidas em três etapas, cada uma delas com duração de uma semana, ao longo de um ano de investigação.

As AEP, por sua vez, se constituíram de etapas de ensino e pesquisa conduzidas pelo próprio professor. Nessas etapas, os professores trabalharam com suas turmas escolares, as temáticas socioambientais discutidas, selecionadas e planejadas em oficinas anteriores, com o propósito de construir uma compreensão cada vez mais clara das dificuldades, dilemas e pressupostos teóricos que as embasavam. Nos períodos de AEP, os professores construíam e reconstruíam suas práticas de ensino com temáticas socioambientais, problematizando os seus eixos orientadores e práticos, ou seja, a investigação se desenvolveu pela reflexão na ação e sobre a ação, durante e após a realização das práticas de ensino dos professores. Ao todo foram 17 etapas de AEP, desenvolvidas, cada uma, em períodos de 15 dias.

\footnotetext{
${ }^{3}$ Um grupo de 15 professores de $1^{\mathrm{a}}$ à $5^{\mathrm{a}}$ série do ensino fundamental, com formação em Pedagogia, Letras e Matemática, 3 professores universitários e 5 estudantes de licenciatura reunidos voluntariamente. O nome de cada um dos participantes enunciados neste trabalho são fictícios, com vistas a preservar suas identidades.
} 
As OSE desenvolveram-se em Parceria Colaborativa, por meio de socialização e reflexão coletiva das experiências pedagógicas vividas durante cada AEP anterior. As OSE foram realizadas ao longo de 17 encontros, alternados com períodos de AEP. Nesses encontros, cada professor relatava ao grupo as experiências vividas com o ensino escolar na quinzena anteriormente transcorrida, num compartilhamento de experiências e reflexões problematizadoras, buscando: (i) a construção de uma compreensão, cada vez mais ampla e clara, dos fatos e processos desenvolvidos com o ensino da temática ambiental, na AEP anterior; (ii) a construção coletiva de ideias, estratégias e sugestões a partir de indagações e reflexões conduzidas pelo grupo sobre dificuldades e desafios surgidos na prática; e, (iii) a reconstrução dos planos de ensino socioambientais.

Em resumo, as OSE se caracterizaram: (i) pela socialização dos registros acerca dos acontecimentos da ação escolar; (ii) por reflexões coletivas, em Parceria Colaborativa, sobre os acontecimentos e as reflexões desenvolvidas pelo professor na e após a ação escolar; e, (iii) pelo replanejamento da ação. Configurava-se como uma avaliação compartilhada com foco, principalmente, nos conflitos, dificuldades e sucessos. Traduziu-se em um momento de reflexão colaborativa em que se construíam ideias e sugestões que, ao serem apreciadas coletiva e colaborativamente, culminavam na reelaboração do plano de ação para a AEP seguinte, numa dinâmica espiralar de ação e reflexão (Figura1).

\section{O processo formativo}

$\mathrm{Na}$ construção dos planos de ensino de temáticas ambientais durante a formação desenvolvida na primeira OFD, discutimos e selecionamos temas socioambientais, definindo, paulatinamente, a partir das reflexões feita nas OSEs, estratégias didático-pedagógicas para o ensino nas escolas.

Inicialmente, como discutiremos neste item, foram problematizados temas organizados sem levar em conta possíveis relações com outros temas ambientais e sem considerar as dimensões econômicas, políticas e culturais relacionadas aos mesmos. Os temas eram discutidos como se fossem gerados e desenvolvidos de forma isolada e desvinculada do contexto histórico, como evidencia o diálogo abaixo:

[...] não dá para ensinar este tema junto com os conteúdos porque eles não fazem parte do currículo e nós já temos muito conteúdo para tratar [...] en não vou trabalhar o desmatamento, este fica na questão regional eu vou trabalhar alimento que é o ponto seguinte do programa [...] [Profa. Marlúcia]

[...] Marlúcia! o tema alimento também tem caráter regional porque é uma característica da região produzir alimentos [...] [Profa. Norma]

[...] mas eu tenho que vencer o programa curricular [...] [Profa. Marlúcia]

[...] Marlúcia! [...] Para produzir alimento o agricultor e o pecuarista vão desmatar a floresta [...] então está relacionado $[. .$.$] o desmatamento com o alimento$ 
[...] o pecuarista não está muito preocupado com a alimentação do povo da região, ele está preocupado é com seu lucro. [Profa. Paula]

Voltada apenas para os aspectos normativos do processo educacional, a professora Marlúcia compartilha a visão segundo a qual o currículo é apenas um conjunto fechado de conteúdos elencados no documento oficial. Em se tratando do trabalho pedagógico, ela anuncia, de forma indireta, que é preciso seguir o currículo oficial. Em sua fala, emprega conceitos derivados da pedagogia tradicional os quais, remetendo a uma visão mais usual do processo escolar, sugerem que o conjunto dos conteúdos oficiais reduz-se a um "programa" de temas sequenciados, pontualmente, para serem obrigatoriamente ensinados, ao longo do ano letivo.

$\mathrm{Na}$ abordagem do tema ambiental, a professora, por um lado, descarta o tema desmatamento, situando-o como questão regional que não está contemplada no rol de conteúdos a serem ensinados. Por outro lado, ao optar por tratar do tema alimento, evidencia a dificuldade em perceber a relação entre este e o desmatamento enquanto temas que se interrelacionam como problemáticas regionais. A força da oficialidade curricular a impede de construir tal relação. Comumente, por não perceberem estes e outros temas como elementos curriculares, os professores não conseguem estabelecer possíveis relações entre os temas selecionados. No caso em análise, a professora não identifica, por exemplo, uma relação entre horta escolar e desmatamento; horta escolar, desmatamento e pobreza; desmatamento e enchente; enchente e produção de alimentos etc.

A interação dialógica e reflexiva entre os professores, ao problematizarem a opção didática da professora, no que se refere à sistematização dos saberes, à reorganização do conhecimento etc., promoveram o debate sobre outras dimensões das questões socioambientais em discussão, como, por exemplo, o interesse do pecuarista pelo lucro financeiro em detrimento da alimentação da população regional. São discussões que, de certa forma, ficaram veladas no processo educacional desenvolvido pela professora Marlúcia.

A sequência de problematizações feitas pelo grupo de professores foram deixando evidente a importância do diálogo reflexivo crítico como elemento mediador na sistematização de saberes regionais e educacionais mobilizados pelo Grupo. Neste sentido, a professora sugere:

[...] tem umas coisas que a sua apresentação suscita [...] começar a pensar as vinculaçöes que eles [os alunos] podem fazer até chegar à questão ambiental [...] por exemplo, nessa questão da alimentação [...] você pode discutir muito bem a distribuição geográfica das alimentaģões... [Profa. Norma].

[...] podem fazer tarefas extraclasse [...] eles [os alunos] podem fazer levantamento dessa questão, da cultura alimentar, da migração [...] o que é que foi introduzido aqui de alimentação que não tinba antes [...] perguntar aos antigos o que se comia antes... [Profa. Marlúcia]

[...] você pode perguntar para eles: - de onde vêm os alimentos? [...] para fazer a relação com a producão de alimentos, com o comércio de alimentos, desenvolver um trabalho na feira, no supermercado [...] de onde vêm os alimentos que nós comemos aqui na região? [Prof. Ricardo]. 
[...] não existirá uma relação entre desmatamento e alimentos que nós possamos discutir com os alunos quando trabalharmos a horta escolar? [...] para produzir alimentos o que se faz com a floresta? [...] e se desmatar tudo, como estamos vendo, o que vai acontecer com as águas quando a chuva cair? [...] [prof. Universitário].

A equipe universitária, durante as OSEs, buscava associar o conhecimento científico pertinente aos temas socioambientais para que as relações entre as temáticas pudessem ser visualizadas, chegando, assim, ao contexto econômico, político e cultural e às consequências produzidas para o quadro social e ambiental, com o propósito de ir construindo uma concepção da dimensão socioambiental através da relação existente entre elementos da realidade regional, tais como: desmatamento, enchentes e a população regional. Neste sentido, buscávamos demonstrar, por meio de projeção de textos em slides, de vídeos e exposições em sala ou de atividades de campo, que o desmatamento produzido para a implantação de grandes fazendas e para a atividade agropecuária destrói a cobertura vegetal, facilitando a erosão, o assoreamento dos rios e, consequentemente, provocando o fenômeno das enchentes. Essas reflexões foram feitas na tentativa de possibilitar a percepção dos professores quanto às relações entre os fenômenos. Alguns professores chegaram a esboçar esta relação em suas falas, porém, na construção do plano de ensino e no desenvolvimento da prática docente tal reflexão não emergia, como evidencia o comentário:

[...] quando eu estou dando aula... não me vem à cabeça uma maneira de ensinar envolvendo a politica, eu me envolvo com as explicações do conteúdo curricular, que é o que eu sempre fiz [...] a relação com a política e com o poder econômico ainda não consigo fažer muito bem [...] en acho que eu não sei fazer isso [...] [Profa. Mara].

Nesta fala evidencia-se a força de uma prática pautada na racionalidade técnica presente no currículo oficial. Tal como discutido por Contreras (2002), alguns conteúdos são considerados como os únicos a serem trabalhados no processo formal docente, evidenciandose como dificuldades que se interpõem entre a tomada de decisão do professor e a sua prática escolar. Tanto os temas como as estratégias, na forma como inicialmente eram planejados, se configuravam como predominantemente isolados e pontuais, desprovidos de iniciativas ou de tentativas do professor em imprimir um sequenciamento temático. Esta questão se revela na narrativa de um professor de uma escola do campo:

[...] depois de trabalhar o desmatamento e a producão de carvão, mostrar a devastação e a poluição do ar, en vou abordar a situação do lixo na vila e depois do igarapé que passa lá [...] e que todos tomam banho. É para onde está indo o esgoto da vila [...] um outro problema sério que existe lá é a criaģão de pequenos animais [...] quando eu entrar no tema de ciências, que trata de animais, quero ensinar sobre a criação de animais... [Prof. Alberto].

O professor, na organização das temáticas ambientais para ensino, vai pontuando tema após tema, fazendo a relação entre saúde e criação de animais, porém, não visualiza a possibilidade de relacionar, numa sequência, as demais temáticas planejadas, permanecendo uma 
organização e uma abordagem de ensino pontuais. Em geral, as estratégias de ensino desenvolvidas pelos professores se esgotam no tratamento estrito da temática escolhida, limitando-se a atividades pontuais.

Com o avanço do ensino, da pesquisa e das reflexões coletivas, as estratégias de ensino passaram a se deslocar para atividades externas ${ }^{4}$, aproximando este dos problemas sociais. Refazendo o seu plano de ensino, a professora Helena comenta:

\begin{abstract}
Quando eu falei que estava neste Grupo [...] a diretora foi mais flexivel [...] quando eu falei que queria levar os alunos para verem a situação ambiental do bairro ela não discutiu e até incentivou [...] vou tratar do lixo, do esgoto, de como as pessoas tratam estas coisas, relacionar com a coleta e o destino e de onde vem o lixo... aí eu entro na questão do consumo [...] para relacionar com o conteúdo eu vou pedir para eles escreverem sobre o que viram no passeio [...] [Profa. Helena].
\end{abstract}

O debate permanente do Grupo e o contexto em que este se desenvolve vai empoderando a professora na negociação com a gestão escolar sobre as suas atividades, construindo uma certa autonomia na condução de suas ações docentes. Neste relato, emerge a influência da universidade, por seu status acadêmico, na relação entre professores e a gestão escolar, facilitando a mudança de estratégias de ensino tradicional para estratégias de ensino alternativas. Destaca-se, desta forma, um importante papel que a instituição de ensino superior (IES) pode exercer no desenvolvimento de determinadas relações escolares. Por outro lado, a adoção de ensino com atividades externas - da mesma forma que a abordagem da relação entre lixo, como problema ambiental local, e consumo como a origem cultural - evidencia não apenas uma abertura da visão e da proposta de ação da professora, mas, também, a influência das atividades vivenciadas no Grupo de Pesquisa. Evidencia-se, desta forma, uma mudança na prática de ensino da professora, em direção à melhoria de suas próprias práticas.

As atividades externas organizadas pelos professores foram adquirindo, também, a função de aproximar o desenvolvimento do processo ensino-aprendizagem aos problemas socioambientais regionais, tais como os problemas com o lixo, com a enchente e com o consequente (re)alojamento insalubre das famílias desabrigadas. A professora Roberta, por exemplo, ao redirecionar o local da aula, retomando uma atividade de ensino já realizada anteriormente, argumenta:

Vou voltar com a aula sobre a enchente [...] a aula vai ser lá no acampamento dos desalojados, quero mostrar as condições das pessoas que estão lá e como o município, o prefeito vem tratando eles [...] os alunos vão entrevistar os acampados para depois escreverem sobre a situação [...] [Profa. Roberta].

\footnotetext{
${ }^{4}$ Atividades didático-pedagógicas ligadas ao ensino escolar desenvolvidas fora do espaço da sala de aula ou da escola.
} 
O replanejamento da ação docente, a partir da reflexão coletiva e crítica, em que as dimensões sociais e políticas são destacadas e problematizadas, permitiu aos professores visualizarem novas possibilidades de abordagem didática da temática em ensino, assim como rever estratégias anteriormente adotadas. Dessa forma, os professores vão se desprendendo dos currículos oficiais, ao mesmo tempo que vão incrementando-os com suas escolhas temáticas e novas estratégias didáticas. Os espaços externos vão tomando importância enquanto palco de ações didáticas e as atividades externas vão se intensificando à medida que o processo de reflexão coletiva, em Parceria Colaborativa, vai se fortalecendo e promovendo trocas de experiências e reflexões cada vez mais questionadoras ou mais críticas. Além disso, a Parceria Colaborativa vai permitindo a visualização de relações contextuais sobre os problemas ambientais tratados no ensino, conforme se pode constatar no excerto abaixo:

[...] a construção de um conhecimento sobre a importância didática dessas atividades para o conbecimento da região e para o envolvimento dos alunos no processo escolar [...] e, também, para o ensino sobre as causas, que eu não conseguia tražer para o meu ensino, como o papel dos políticos e dos comerciantes [...] dos empresários [...] [Profa. Marlúcia].

Ao buscar construir, durante as OSEs, uma base reflexiva sobre o ensino pontual e fragmentado no trabalho com a horta, os professores vão construindo posicionamentos mais críticos sobre questões sociais e políticas envolvidas no tema ensinado e sobre o trabalho pedagógico que vinham conduzindo. Tal processo vai ocorrendo à medida que as reflexões avançam sobre relações entre fenômenos sociais e ambientais, evidenciando a importância da reflexão crítica e colaborativa no processo de inserção da EA crítica na educação básica e no processo de constituição do professor educador ambiental crítico. As reflexões mostram que, aos poucos, a dimensão social foi tomando espaço em nossos diálogos:

Eu acho que nós podemos discutir de onde vêm os alimentos [...] mostrar que muitos alimentos que comemos não são produzidos aqui em Marabá... vêm de fora, de outras regiões... [Profa. Norma].

[...] pode se ligar, também, com a fome, dai com a pobreza [...] antigamente eu via muitas usinas de arroz em Marabá, em quase cada esquina tinha uma [...] agora não se vê mais, é só boi! Só pasto. [...] que gera pouco emprego porque um vaqueiro sozinho consegue cuidar de uma infinidade de bois [...] [Profa. Roberta].

São reflexões que vão, não apenas enriquecendo criticamente a maneira de pensar dos professores sobre o quadro econômico regional e as consequências deste para o quadro social e ambiental, mas, também, promovendo uma troca de ideias e de experiências que possibilitam o desenvolvimento dos próprios professores no que se refere à sistematização teórica de estratégias de ensino, adotadas com base na mobilização de elementos e processos socioambientais regionais. Essas práticas apontam para a reorganização dos saberes gerados na dinâmica cotidiana, contribuindo para a sistematização dos conhecimentos próprios sobre características e problemas da região e possibilitando a organização de um processo de ensino valorizador dos elementos e da dinâmica regional, à media que a reflexão vai se tornando cada vez mais crítica. 
Entretanto, no início dos trabalhos de campo, durante as atividades desenvolvidas na primeira OFD e nas primeiras OSEs, era possível identificar um quadro de ações e concepções que se alinhava com os princípios próprios de uma EA conservadora, como evidencia o depoimento:

[...] eu faço a pauta todos os dias [...] fica no canto do quadro, nela vem: oração, chamada, correção, leitura, português, recreio [...] pra mim seria uma forma deles começarem a se organizar [...] para o aluno ter ciência [...] como ele [o conteúdo] vai ser trabalhado [...] eu fiquei pensando depois do último encontro nosso, se isso não era uma forma bierarquizada demais, sequenciada demais de tratar o conteúdo [...] mas penso que é necessário [...] a gente tem que ver que tem um horário pra estudar, pra brincar [...] $e$ também pode estudar e brincar ao mesmo tempo, mas [...] ciente do que está fazendo [...] porque é um problema muito sério, as crianças não têm compromisso com o seu aprendizado [...] para poder perceber que o aprendizado é deles [...] a rotina, é uma necessidade, todo mundo tem que ter sua rotina [...] [Profa. Paula].

A professora se sente provocada pelo diálogo desenvolvido no Grupo ao falar da fragmentação do conteúdo a ser ensinado e identifica a necessidade de sistematizar a realidade. Em seu relato, imediatamente acima, a professora levanta hipóteses sobre a forma fragmentada de organizar conteúdos e temas. Como ela própria diz, a "pauta" com os temas que serão tratados na aula, é escrita num "canto" da lousa, com as ações do dia elencadas sequencialmente. Trata-se de um local em que a "pauta" pode permanecer até o final da aula, indicando os limites necessários, tanto para ela como para os alunos, oferecendo-lhe uma sequenciação segura de suas atividades. Tal prática é indício da força com que princípios conservadores dominam a concepção de organização do trabalho didático-pedagógico-escolar. A rotina e o hábito arraigados na forma de organizar e conduzir a prática docente estão presentes nos pressupostos que os professores empregam em suas atividades, mostrando como o ensino escolar está, em grande parte, calcado em teorias e saberes tácitos que dificultam aos professores a percepção dos saberes que guiam suas práticas.

No decorrer do processo de reflexão coletiva, esse quadro vai mudando à medida que a prática reflexiva crítica vai se desenvolvendo nas trocas de ideias e saberes, através da socialização das experiências. Os professores passam a adotar, cada vez mais, práticas de ensino que expressam relações entre diferentes temáticas ambientais. Buscam visualizar relações contextuais inerentes à temática ambiental ensinada, identificando, no cotidiano escolar e durante as OSEs, práticas que refletem a racionalidade técnica comprometida com o cumprimento do currículo oficial. Em análise avaliativa de sua trajetória no Grupo, a professora Norma assim expressa:

Só agora, após 12 anos na educação, pude parar e refletir sobre minha carreira docente. E hoje após quase um ano de debates, troca de ideias, de experiências, e muitas reflexões sobre questões diversas no campo do ensino, tentando encontrar possiveis respostas, acredito que estamos no caminho certo para encontrá-las [...] Estes momentos de pesquisa-ação fortaleceram nosso trabalho, transformei minha sala de aula em campo de pesquisa constante, não é fácil, mas ajuda a construir um novo comportamento profissional, entender as próprias dificuldades, fragilidades e, também, as potencialidades, buscando sempre solução para os problemas identificados. 
Em outro instante de reflexão avaliativa sobre o papel das atividades colaborativas na sistematização de ideias e no redirecionamento da prática vivenciadas no Grupo, surgem relatos sobre a importância do papel da I-A em Parceria Colaborativa para a mudança da prática dos professores:

\begin{abstract}
[...] as práticas individuais compartilhadas, os erros cometidos, os avancos e retrocessos de cada integrante nos fazem refletir não só sobre nossa ação, mas sobre cada uma das açoes, interferindo, sugerindo e revendo as práticas ambientais [...] hoje eu vejo que todos os profissionais da educação deveriam ter a oportunidade de vivenciar tais experiências, pois tenho crescido muito profissionalmente, desenvolvido a capacidade de observar mais minhas práticas, rever o que planejo, ver o que não foi bom onde posso e preciso melhorar [...] [Profa. Norma].
\end{abstract}

A mudança didática de uma posição pontual e fragmentada para uma posição mais dinâmica e relacional do processo de ensino de temas socioambientais vai sendo construída com todas as dificuldades próprias de uma formação cujas bases conceituais e práticas ainda estão em curso. Os diálogos desenvolvidos em Parceria Colaborativa vão proporcionando aos professores oportunidades de reorganização dos conhecimentos históricos sobre a região, trazendo-os para os processos de ensino, ao mesmo tempo em que compartilham ideias e práticas sobre possíveis e melhores estratégias de ensino.

Essas atitudes promovem uma mudança de rumo nos planejamentos e nos modos de ensinar, possibilitando uma formação crítica, contínua e coletiva concomitante à melhoria das práticas profissionais docentes, através da reflexão crítica e da I-A em Parceria Colaborativa.

\title{
Considerações finais
}

As análises realizadas permitiram identificar mudanças no processo de ensino dos professores, bem como, algumas dificuldades que se colocaram antes e durante o processo, sobretudo dificuldades de ordem contextual, de natureza social, política, administrativa e formativa as quais incidem sobre suas concepções socioambientais e educacionais, dificultando-lhes o desenvolvimento de projetos de ensino inovadores. Esta constatação aponta para a necessidade de implementação de estudos e programas de formação continuada pelas instituições e órgãos gestores, assim como para a necessidade de implementação de políticas públicas efetivas, permanentes e contínuas destinadas a essa etapa de formação de professores, tendo a I-A e a Parceria Colaborativa entre escola e universidade como eixo teórico-metodológico estratégico e a EA crítica como referencial do processo formativo do professor educador ambiental.

Durante este trabalho todos os registros das AEPs eram trazidos pelos professores para reflexão na OSE seguinte numa dinâmica de: planejamento $\rightarrow$ ação $\rightarrow$ reflexão $\rightarrow$ replanejamento $\rightarrow$ ação $\rightarrow$ reflexão, sugerindo um modelo espiralar de desenvolvimento da investigação (Figura 1), de acordo com os modelos de McNiff (1988) e Contreras (1994). Entre a reflexão na OSE e a ação posterior na AEP sempre existiu um replanejamento provocado pela reflexão em Parceria Colaborativa, o qual permitia indagar sobre a prática, no que concerne a propósitos, resultados e abordagens. Esta proposta deslocou a trajetória da prática do professor do curso, 
inicialmente prevista/planejada, para um novo curso, uma nova trajetória. Esse deslocamento proporcionou, no plano subjetivo, uma potencial oportunidade para a mudança individual e coletiva, ou seja, para a construção coletiva de novos saberes, de novas concepções, de novos princípios e novos fazeres, conduzindo ao enriquecimento dos saberes docentes construídos na prática docente, como discutido por Tardiff (2002). Certamente, em se tratando de um processo humano, esse movimento não é homogêneo e sua intensidade e velocidade são variáveis de indivíduo para indivíduo, de coletivo para coletivo.

A pesquisa confirmou-nos a tese de que os itens de replanejamento contínuo da ação dos professores do Grupo, ou seja, as estratégias de ensino e de relacionamento com os outros atores - nem sempre constituídos apenas de alunos -, as mudanças de "rota" dos temas e suas relações com o conteúdo específico ou com outros temas socioambientais foram se intensificando à medida que a interação dialógica desenvolvida na reflexão coletiva avançava nas OSEs. Portanto, as atividades em Parceria Colaborativa tiveram um papel importante no desenvolvimento dos professores, contribuindo, pelas reflexões compartilhadas e pelas atividades embasadas nos princípios da EA crítica, para o crescimento do Grupo, com a incorporação das relações econômicas, políticas, sociais e culturais e a compreensão da importância do tratamento dessas questões no ensino e na constituição do professor como educador ambiental crítico.

As reflexões e indagações mostraram, ainda, a necessidade de uma prática contínua para o desenvolvimento de EA na escola, ou melhor, a necessidade de um ensino permanente de questões ambientais com práticas e temáticas interrelacionadas. Tal questão traz para o cenário escolar a necessidade de uma EA permanente, isto é, aponta para a necessidade de desenvolvimento de uma concepção segundo a qual o ensino da temática ambiental e as ações e relações socioambientais cotidianas são permanentemente praticadas na escola, através de uma compreensão integrada dos processos socioambientais e seus problemas. Isso exige uma mudança de concepção educacional que projete uma perspectiva de EA crítica, como discutida por Carvalho (2000) e Tozoni-Reis (2008). Ou seja, esta mudança só pode ser efetiva se a ação ou ações educativas respeitarem os diferentes atores do processo, propiciando-lhes reflexões a partir de uma abordagem crítica e integradora das questões econômicas, políticas, sociais e culturais relacionadas ao problema socioambiental trabalhado.

As etapas de reflexão coletiva em Parceria Colaborativa realizadas durante a investigação auxiliaram na compreensão do Grupo em relação à necessidade de integração do conhecimento específico com o tema socioambiental, enfraquecendo a ideia de EA como disciplina. As reflexões produzidas geraram teorias através da troca de ideias entre os membros do grupo e da sistematização, replanejamento e confrontação de ações e posições durante a realização da AEP seguinte. São teorias que tratam de como ensinar questões socioambientais numa perspectiva crítica; de como trabalhar o ensino com uma visão integrada sobre as ações humanas que criam os impactos socioambientais. Para Zeichner (1993, p. 21):

[...] a teoria pessoal de um professor sobre a razão porque uma lição correu pior ou melhor do que o esperado, é tanto teoria como as teorias geradas nas universidades sobre o ensino da leitura: ambas precisam ser avaliadas quanto a sua qualidade, mas ambas são teorias sobre a realização de objetivos educacionais. 
O processo de reflexão crítica, coletiva e colaborativa sobre o tema lixo no ensino escolar, discutido neste texto, permitiu-nos, também, perceber que a recorrência desta temática de ensino se deve ao fato de este tema se situar num plano ambiental mais próximo do professor. O lixo, como outros temas dessa natureza, é um problema que está à porta das pessoas, dentro das escolas e em muitas esquinas das cidades da região. Por isso, torna-se um tema premente, por ser mais familiar, favorecendo, assim, sua mobilização no ensino através de atividades que vão desde práticas de sala de aula até ações na escola e na comunidade como um todo. O que não está sendo alcançado pela crítica e pelo ensino em abordagens conservadoras são análises reflexivas críticas que permitam a problematização e sistematização coletiva das origens desses problemas, ou melhor, das relações e dimensões econômicas, políticas e culturais envolvidas nesta problemática regional. Tal procedimento deve ser realizado numa perspectiva crítica e emancipadora, rumo a um melhor ensino escolar de temáticas ambientais, por meio do qual os estudantes possam construir uma consciência crítica sobre o tema.

Durante o processo de reflexão, em Parceria Colaborativa, a temática lixo, por exemplo, foi sendo aos poucos vinculada a outras temáticas, como o consumo, a compostagem, a urbanização etc., sempre estabelecendo a interconexão deste tema, tanto com a dimensão física quanto com a dimensão social do ambiente. O professor, pelo processo colaborativo, voltouse, de forma crítica e questionadora, para o tratamento pedagógico da compostagem, e desta para o reaproveitamento do lixo orgânico e para a construção da horta escolar. Incluiu-se nesta discussão a produção de alimentos e seu comércio, chegando aos preços e ao consumo, ou seja, à economia, e, por essa via, ao consumismo enquanto prática cultural.

Desta forma, as reflexões coletivas desenvolvidas sobre as relações e implicações dos problemas socioambientais cotidianos possibilitaram que os professores visualizassem a dimensão econômica como uma das causas do problema ambiental do lixo, em estreita relação com a propaganda, o consumo e hábitos culturais cotidianos conduzidos pela população em geral. Em síntese, os professores puderam visualizar todos esses elementos articulados com a problemática do lixo como "resposta" da população ao descaso administrativo adotado pelos gestores oficiais dos processos urbanos.

As análises realizadas neste trabalho apontam para a necessidade de proporcionar ao professor, por meio de políticas públicas consequentes, condições materiais e intelectuais para que possa, em Parceria Colaborativa com seus pares, investigar sua prática de ensino: conhecê-la apropriadamente, proporciona-lhe melhores condições para mudá-la, para melhorá-la.

Os professores integrantes do Grupo, com todas suas idiossincrasias e reflexões sobre suas práticas, evidenciaram a importância das reflexões coletivas para seu processo formativo, a partir dos princípios de uma EA crítica.

Por último, a partir das análises e discussões realizadas ao longo deste trabalho, ressaltamos a importância do processo permanente de I-A em Parceria Colaborativa, em que a troca de ideias e de experiências levam à reconstrução coletiva de estratégias adotadas para a melhoria do ensino. Como apontam Carr e Kemmis (1997), Zeichner (1993), e outros, tal processo, enquanto promotor da formação do professor educador ambiental, favorece a inserção da EA na dinâmica escolar pela reflexão crítica, coletiva e permanente da ação docente. Favorece, portanto, a mudança e a melhoria contínua da prática docente dos envolvidos na Parceria Colaborativa. Entendemos que a eficácia desse processo será tanto maior quanto mais contínuo e permanente for o seu desenvolvimento. 


\section{Agradecimentos}

Os autores agradecem o apoio da Coordenação de Aperfeiçoamento de Pessoal de Nível Superior (CAPES).

\section{Referências}

CARR, W.; KEMMIS, S. Becoming critical: education, knowledge and action research. London: The Falmer Press, 1997.

CARR, W.; KEMMIS, S. Teoria crítica de la ensenãnza: la investigación-acción en la formación del profesorado. Barcelona: Martinez-Roca, 1988.

CARVALHO, I. C. M. A invenção ecológica: narrativas e trajetórias da educação ambiental. Porto Alegre: Ed. UFRGS, 2001.

CARVALHO, I. C. M. Questão ambiental e a emergência de um campo de ação políticopedagógico. In: LOUREIRO, C. F. B.; LAYRARGUES, P. P.; CASTRO, R. S. (Org.).

Sociedade e meio ambiente. São Paulo: Cortez, 2000. p. 53-65.

CONTRERAS, J. A autonomia de professores. São Paulo: Cortez, 2002.

CONTRERAS, J. La investigacion en la acción: ¿que és? Cuadernos de Pedagogia, Madrid, n. 224, p. 8-12, 1994.

CRESPO, S.; LEITÃO, P. O que o brasileiro pensa de ecologia. Rio de Janeiro: Iser, 1993.

DICKEL, A. Que sentido há em se falar em professor-pesquisador no contexto atual?: contribuições para o debate. In: GERALDI, C. M.; FIORENTINI, D. P.; PEREIRA, E. M. A. (Org.). Cartografias do trabalho docente: professor(a)-pesquisador(a). Campinas: Mercado de Letras, 2001. p. 33-71.

FARIAS, C. R. O.; FREITAS, D. Educação ambiental e relações CTS: uma perspectiva integradora. Ciência \& Ensino, Piracicaba, v. 1, n. esp., p. 1-13, 2007.

FREIRE, P. Pedagogia do oprimido. 20. ed. Rio de Janeiro: Paz e Terra, 1992.

GRÍGOLI, J. et al. A formação do professor investigador na escola e as possibilidades de pesquisa colaborativa: um retrato sem retoques. Revista Lusófona de Educação, Lisboa, n. 10, p. 81-95, 2007.

GUIMARÃES, M. A formação de educadores ambientais. Campinas: Papirus, 2004.

GUTIERREZ, F.; PRADO, C. Ecopedagogia e cidadania planetária. São Paulo: Cortez, 1999.

HÉBÈTTE, J. Cruzando a fronteira: 30 anos de estudo do campesinato na Amazônia. Belém: Edufpa, 2004. 4 v.

LOUREIRO, C. F. B. Trajetórias e fundamentos da educação ambiental. São Paulo: Cortez, 2004. 
MARTINS, J. P. A. Educação ambiental crítica e formação de professoras fundada na investigação-ação e na parceria colaborativa. 2016. Tese (Doutorado) - Universidade Metodista de Piracicaba, Piracicaba, 2016.

McNIFF, J. Action research: principles and practice. London: MacMillan, 1988.

NACARATO A. M. Escola como locus de formação e de aprendizagem: possibilidades de riscos da colaboração. In: FIORENTINI, D.; NACARATO, A. M. (Org). Cultura, formação e desenvolvimento profissional de professores que ensinam matemática. Campinas: Musa, 2005. p. 175-195.

PEREZ-GÓMEZ, A. O pensamento prático do professor: a formação do professor como profissional reflexivo. In: NÓVOA, A. Os professores e sua formação. Lisboa: Dom Quixote, 1992. p. 93-114.

PIMENTA, S. G.; GHEDIN E. Professor reflexivo no Brasil: gênese e crítica de um conceito. São Paulo: Cortez, 2002.

SCHNETZLER, R. P. Concepções e alertas sobre formação continuada de professores de química. Química Nova na Escola, São Paulo, n. 16, p. 15-20, 2002.

SCHNETZLER, R. P. A investigação-ação e o desenvolvimento profissional docente. Piracicaba: UNIMEP, 2000.

STENHOUSE, L. La investigación como base da la enseñanza. Madrid: Morata, 1993.

TARDIF, M. Saberes docentes e formação profissional. Petrópolis: Vozes, 2002.

TOZONI-REIS, M. F. C. Metodologias aplicadas à educação ambiental. Curitiba: IESD Brasil, 2008.

TRISTÃO, M. Educação ambiental na formação de professores: redes de saberes. São Paulo: Annablume, 2004.

ZEICHNER, K. M. A formação reflexiva de professores: idéias e práticas. Lisboa: EDUCA, 1993.

Artigo recebido em 29/08/2017. Aceito em 16/01/2018.

Contato: Universidade Federal do Sul e Sudeste do Pará, Instituto de Ciências Humanas, Faculdade de Ciências da Educação, Folha 31, Quadra 07, Lote Especial Nova Marabá, Marabá, PA 68507-590, Brasil. 